\title{
EL DERECHO A LA SEGURIDAD SOCIAL ANTE EL COMITÉ EUROPEO DE DERECHOS SOCIALES*
}

\author{
The right to Social Security before \\ the European Committee of Social Rights
}

\author{
Verónica Lidia Martínez Martínez \\ Profesora-Investigadora doctora de la Universidad Anáhuac \\ Investigadora Nacional del Sistema Nacional de Investigadores \\ del Consejo Nacional de Ciencia y Tecnología (México) \\ marb_cap@hotmail.com
}

http://dx.doi.org/10.18543/ed-67(1)-2019pp259-291

Recibido: 10.10 .2018

Aceptado: 21.06.2019

\section{Resumen}

A partir de un breve estudio de la Carta Social Europea de 1961, sus protocolos y la Carta Social Europea Revisada, en el presente trabajo, con base en la interpretación autorizada que hace el Comité Europeo de Derechos Sociales al momento de pronunciarse sobre los informes presentados por los Estados, se exponen los requerimientos mínimos que deben reunir los sistemas de seguridad para ajustarse a la Carta de 1961 y a la Carta revisada, así como la justiciabilidad del derecho a la seguridad social en el procedimiento de reclamaciones colectivas.

\section{Palabras clave}

Comité Europeo de Derechos Sociales; Carta Social Europea; Carta Social Europea Revisada; seguridad social; sistema de informes; quejas colectivas.

* Cómo citar / Citation 'Chicago-Deusto' (Autor-fecha / Author-date / Lista de referencias / Reference list entries): Martínez Martínez, Verónica Lidia. 2019. «El Derecho a la Seguridad Social ante el Comité Europeo de Derechos Sociales». Estudios de Deusto 67, n. ${ }^{\circ}$ 1: 259-291. http://dx.doi.org/10.18543/ed-67(1)-2019pp259-291. 


\section{Abstract}

Based on a brief study of the European Social Charter, its protocols and the European Revised Social Charter, in this paper, based on the authoritative interpretation made by the European Committee of Social Rights when deciding on the reports submitted by States, the minimum requirements that security systems must meet to comply with the 1961 Charter and the revised Charter, as well as the justiciability of the right to social security based on the system of collective complaints.

\section{Keywords}

European Committee of Social Rights; European Social Charter; Revised European Social Charter; social security; reporting system; collective complaints. 
Sumario: I. El Consejo de Europa. II. Protocolos de la Carta Social Europea. III. CARTA Social Europea REVISADA. IV. El SisteMA DE INFORMES Y EL DERECHO A LA SEGURIDAD SOCIAL. V. El PROCEDIMIENTO DE RECLAMACIONES COLECTIVAS Y EL DERECHO A LA SEGURIdad Social. VI. Problemática de los mecanismos del Comité Europeo De Derechos Sociales. VII. Fuentes de información.

\section{EL CONSEJO DE EUROPA}

El Consejo de Europa (CdE) -creado el 5 de mayo de 1949- se conforma por 47 miembros en los que se incluyen los 28 Estados miembros de la Unión Europea (UE). El CdE se constituye como una organización internacional de carácter regional y de pleno derecho, ajena a la UE.

Los principales tratados de derechos humanos de corte social del CdE son la Carta Social Europea (CSE), sus protocolos y la Carta Social Europea Revisada (CSER) que en comunión con el Código de la Seguridad Social, su protocolo adicional y el Código de la Seguridad Social Revisado constituyen el entramado básico en materia de seguridad social.

La CSE, a la que se considera como la Constitución Social de Europa, se redactó en Turín el 18 de octubre de 1961 con la intervención de la Organización Internacional del Trabajo, y se firmó en Estrasburgo el 27 de abril de $1978^{1}$. En la actualidad la CSE ha sido aceptada por cuarenta y tres Estados de los cuarenta y siete Estados miembros del $\mathrm{CdE}^{2}$.

La CSE se compone de un preámbulo, cinco partes y un anexo. La segunda parte de la CSE se integra con diecinueve artículos, que se corresponden con los diecinueve objetivos de la primera parte, los cuales se perseguirán por los Estados miembros por todos los medios apropiados.

Los derechos reconocidos en la segunda parte de la CSE son: el derecho al trabajo (artículo 1); el derecho a condiciones de trabajo equitativas (artículo 2); el derecho a la seguridad e higiene en el trabajo (artículo 3); el derecho a una remuneración equitativa (artículo 4); el derecho a la libertad sindical (artículo 5); el derecho a la negociación colectiva (artículo 6); los derechos de los niños

${ }^{1}$ La Carta Social Europea entró en vigor el 26 de febrero de 1965.

2 Albania, Alemania, Andorra, Armenia, Austria, Azerbaiyán, Bélgica, Bosnia y Herzegovina, Bulgaria, Croacia, Chipre, República Checa, Dinamarca, Estonia, Finlandia, Francia, Georgia, Grecia, Hungría, Islandia, Irlanda, Italia, Letonia, Liechtenstein, Lituania, Luxemburgo, Malta, Moldova, Mónaco, Montenegro, Noruega, Países Bajos, Polonia, Portugal, Rumania, Federación de Rusia, San Marino, Serbia, República Eslovaca, Eslovenia, España, Suecia, Suiza, Ex República Yugoslava de Macedonia, Turquía, Ucrania, Reino Unido ha ratificado la Carta Social Europea. Liechtenstein, Mónaco, San Marino y Suiza no se han adherido la CSE. 
y adolescentes (artículo 7); los derechos de las trabajadoras (artículo 8); el derecho a la orientación profesional (artículo 9); el derecho a la formación profesional (artículo 10); el derecho a la protección de la salud (artículo 11), así como el derecho a la asistencia social y médica (artículo 13).

De igual manera en la CSE se reconoce el derecho a los beneficios de los servicios sociales (artículo 14.); los derechos de las personas física o mentalmente disminuidas a la formación profesional y a la readaptación profesional y social (artículo 15.); el derecho de protección a la familia (artículo 16); los derechos de las madres y los niños (artículo 17); el derecho a ejercer una actividad lucrativa en el territorio de otras partes contratantes (artículo 18); los derechos de los trabajadores migrantes (artículo 19); el derecho a la igualdad y a la prohibición de discriminación por razón de sexo (artículo 20), así como el derecho a la información y consulta con los trabajadores o sus representantes de conformidad con la legislación y prácticas nacionales.

La tercera parte de la Carta contiene las obligaciones de los Estados en relación con la CSE; en tanto que la cuarta parte reglamenta el sistema de control de presentación de informes por los Estados miembros. En la parte quinta se regula lo referente a la suspensión de obligaciones en caso de guerra o de peligro público, las restricciones a los derechos y los principios establecidos en la CSE, así como la firma, ratificación, entrada en vigor, enmiendas y denuncias del instrumento en análisis.

Los países que han suscrito la CSE de 1961, a la que se denomina originaria, no se encuentran vinculados por la totalidad de los diecinueve preceptos de la Parte II, puesto que el sistema de ratificación les permite obligarse a cinco de los siete artículos que conforman el núcleo duro de la CSE, el cual se integra por el derecho al trabajo, el derecho de sindicación, el derecho a la negociación colectiva, el derecho a la seguridad social, el derecho a la asistencia social y médica, el derecho de la familia a una protección social, jurídica y económica y el derecho de los trabajadores migrantes y sus familias a la protección y a la asistencia. Asimismo, los Estados deben ratificar un número adicional de artículos o párrafos numerados de la Parte II de la CSE. El número total de artículos y párrafos numerados a los que deben quedar obligados los Estados no tiene que ser inferior a diez artículos o a cuarenta y cinco párrafos numerados ${ }^{3}$.

\section{PROTOCOLOS DE LA CARTA SOCIAL EUROPEA}

El texto de la Carta Social de 1961 constituye un ordenamiento vivo porque ha evolucionado a través de diversas modificaciones efectuadas por la

3 Artículo 20.1 c) de la Carta Social Europea, [Consulta: 30 de septiembre de 2018], disponible en $<$ http://www.acnur.org/t3/fileadmin/scripts/doc.php?file=t3/fileadmin/Documentos/BDL/2002/1934> 
vía de los protocolos y la interpretación autorizada que realiza el Comité Europeo de Derechos Sociales (CEDS) como se analiza en los dos últimos apartados de este trabajo.

El Protocolo Adicional de la Carta Social Europea, cuya adopción data del 5 de mayo de 1988 (y en vigor a partir del 4 de septiembre de 1992) mejora la protección de algunos derechos ya incluidos en la Carta originaria, referentes al derecho al trabajo y a la protección social, en concreto; el derecho a igualdad de oportunidades y de trato en materia de empleo y de formación sin discriminación basada en el sexo; el derecho a la información y a la consulta; el derecho a participar en la determinación y mejora de las condiciones de trabajo y el derecho de las personas ancianas a la protección social.

A través de este protocolo se incorporan cuatro nuevos derechos a la CSE, los cuales son: el derecho a igualdad de oportunidades y de trato en materia de empleo y de profesión, sin discriminación por razones de sexo; el derecho a información y consulta; el derecho a tomar parte en la determinación y mejora de las condiciones de trabajo y del entorno laboral, así como el derecho a la protección social de las personas de edad avanzada.

Por su parte, el Protocolo Adicional a la CSE, aprobado el 21 de octubre de 1991, confirma el papel político del Comité de Ministros y de la Asamblea Parlamentaria como órganos del CdE, además de consignar las funciones del CEDS y del Comité Gubernamental ${ }^{4}$.

Empero, el principal objetivo de este segundo protocolo de la CSE es fortalecer el mecanismo de informes a través de la inclusión de organizaciones internacionales no gubernamentales que se ocupan de analizar los informes que presentan los Estados parte, además de existir la posibilidad de que el CEDS que evalúa los informes, solicite información y aclaraciones complementarias a los Estados 5 .

Por último, el Protocolo Adicional de 9 de noviembre de 1995 (en vigor a partir del $1^{\circ}$ de septiembre de 1998) permite la instauración del sistema de reclamaciones colectivas que complementa el mecanismo de informes establecido desde la adopción de la CSE en 1961.

A diferencia de la Carta originaria, ratificada por la mayoría de los Estados miembros del Consejo de Europa, el Protocolo de 1995 sólo lo han ratificado quince países de los cuarenta y siete Estados miembros del $\mathrm{CdE}^{6}$.

${ }^{4}$ En el Protocolo de 21 de octubre de 1991 cambia el nombre de Subcomité del Comité Social Gubernamental por el de Comité Gubernamental.

5 Artículo 2, inciso 3 del Protocolo de Enmienda a la Carta social Europea, de 21 de octubre de 1991, [Consulta: 29 de septiembre de 2018], disponible en $<$ http://www.acnur. org/t3/fileadmin/Documentos/BDL/2003/1899.pdf?view=>

${ }^{6}$ El Protocolo de 1995 ha sido aceptado por Bélgica, Bulgaria, Croacia, Chipre, República Checa, Finlandia, Francia, Grecia, Irlanda, Italia, Países Bajos, Noruega, Portugal, Eslovenia y Suiza, los últimos catorce países son miembros de la UE. 
Uno de los principales objetivos del proceso de Turín y de la Resolución $2180(2017)^{7}$ de la Asamblea Parlamentaria es la aceptación del Protocolo de 1995 por parte de un mayor número de países, pues ello contribuirá a reducir la carga de trabajo de las autoridades nacionales involucradas en la presentación de informes; provocará una supervisión más efectiva del cumplimiento de los derechos sociales y reducirá la presentación de casos ante los tribunales nacionales y el Tribunal Europeo de Derechos Humanos

\section{CARTA SOCIAL EUROPEA REVISADA}

La Carta Social Europea Revisada (CSER) fue elaborada entre 1990 y 1994 por un específico Comité ad hoc (Charter-Rel), instituido con motivo de la Conferencia ministerial informal sobre derechos humanos celebrada en Roma el 5 de noviembre de $1990^{8}$. Según su mandato, el Comité recibió instrucciones de hacer propuestas para mejorar la eficacia del CSE y el funcionamiento de su maquinaria de supervisión.

En su duodécima reunión (10 a 14 de octubre de 1994), el Comité de Charter-Rel adoptó un proyecto de CSER, el cual se presentó al Comité Ministros

${ }^{7}$ En la Resolución 2180 (2017), El «proceso de Turín»: refuerzo de los derechos sociales en Europa, la Asamblea Parlamentaria del CdE hace un llamamiento a los Estados miembros del CdE para que apoyen, a través de sus gobiernos y parlamentos, los debates y la cooperación iniciados en el marco del Proceso de Turín y procedan de la siguiente manera: 7.1. Contribuir al fortalecimiento de la CSE como un sistema normativo mediante: 7.1.1. Reafirmando los principios de la indivisibilidad e interdependencia de los derechos humanos en el discurso público y en los documentos legislativos y de política; 7.1.2. En el caso de los 13 Estados miembros que aún no lo han hecho, la ratificación de la CSER, para mejorar los niveles de cumplimiento de esta importante norma de derechos sociales; 7.1.3. En el caso de los cuatro países que aún no lo han hecho (Dinamarca, Alemania, Luxemburgo y el Reino Unido), ratificando el Protocolo por el que se modifica la CSE (STE n. ${ }^{\circ}$ 142, «Protocolo de Turín») para permitir la elección de Miembros de la ECSR por la Asamblea, como ya se solicitó en la Recomendación 1976 (2011) sobre el papel de los parlamentos en la consolidación y el desarrollo de los derechos sociales en Europa; 7.1.4. En el caso de los Estados miembros que aún no lo hayan hecho, ratificando el Protocolo Adicional a la CSE que establece un Sistema de Quejas Colectivas (ETS No. 158), a fin de garantizar una supervisión más efectiva del cumplimiento de los derechos sociales; 7.1.5. Participar activamente en las actividades parlamentarias destinadas a promover el sistema de tratados de la CSE y mejorar su aplicación, que la Asamblea organiza regularmente en cooperación con otros órganos del CdE, especialmente el ECSR, y proporciona contribuciones voluntarias para este fin. Vid. Resolución 2180 (2017), El «proceso de Turín»: refuerzo de los derechos sociales en Europa, Asamblea Parlamentaria [Consulta: 24 de agosto de 2018], disponible en $<$ http://assembly.coe.int/nw/xml/XRef/Xref-XML2HTML-en.asp?fileid=23993\&lang=en>

${ }^{8}$ Giovanni Guiglia, «El derecho a la vivienda en la Carta Social Europea: A propósito de una reciente condena a Italia del Comité Europeo de Derechos Sociales» (UNED, Revista de Derecho Público, n. ${ }^{\circ}$ 82, septiembre-diciembre 2011), 548. 
del CdE. El texto intitulado «La versión europea revisada de la CSE», se adoptó el 3 de abril de 1996 y abrió a la firma el 3 de mayo de $1996^{9}$.

Las modificaciones que realiza la CSER a la Carta originaria, son las siguientes ${ }^{10}$ : en el artículo 2 (relativo a condiciones de trabajo equitativas) las vacaciones anuales pagadas pasan de un mínimo de dos a cuatro semanas; en el artículo 3 (derecho a la seguridad e higiene en el trabajo) se obliga a los Estados a instituir de forma progresiva los servicios de salud en el trabajo con funciones esencialmente preventivas y de asesoramiento; en el artículo 7 (derecho de los niños y los adolescentes a la protección) se establece la edad mínima de dieciocho años para acceder a trabajos considerados peligrosos o insalubres (en la Carta originaria no se fijaba edad mínima alguna)

Por su parte, en el artículo 8 de la CSER (derecho de las trabajadoras a la protección por maternidad), la duración del permiso por maternidad pasa de doce a catorce semanas, además se extiende el período durante el cual la mujer embarazada no puede ser objeto de despido (que va desde que notifica el embarazo al empleador hasta el final del permiso de maternidad).

En el numeral 2 del artículo 12 de la CSER se establece que las Partes contratantes se comprometen a mantener el régimen de seguridad social en un nivel satisfactorio, equivalente, por lo menos, al exigido para la ratificación del Código Europeo de Seguridad Social en lugar del Convenio n. ${ }^{\circ} 102$ de la Organización Internacional del Trabajo (OIT) al que hacía referencia la CSE originaria. El Código Europeo de Seguridad Social requiere la aceptación de un número mayor de partes que el Convenio 102 de la OIT, pues seis de las nueve partes deben aceptarse, aunque ciertas ramas cuentan para más de una parte, como por ejemplo, la atención médica cuenta como dos partes, y la edad avanzada cuenta como tres. Cada contingencia establece niveles mínimos de cobertura personal y niveles mínimos de beneficios.

Por añadidura, en el artículo 19 de la CSER (derecho de los trabajadores migrantes y de sus familias a la protección y a la asistencia), ya no se protege sólo a la esposa del trabajador, sino al cónyuge (hombre o mujer) del operario o de la trabajadora ${ }^{11}$.

Tanto la Directiva comunitaria 80/987/CE sobre la protección de los trabajadores en caso de insolvencia del empleador como la Resolución $839(1978)^{12}$

${ }^{9}$ La CSER entró en vigor el $1^{\circ}$ de septiembre de 1999.

${ }^{10}$ Luis Jimena QuesadA, Defensa y garantía de los derechos sociales por el Consejo de Europa: Atención Especial al Comité Europeo de Derechos Sociales, en Carlos L. Alfonso Mellado et al., La jurisprudencia del Comité Europeo de Derechos Sociales frente a la crisis económica (Bomarzo, España, 2014), 58-59.

${ }^{11}$ Idem.

12 A través de la Recomendación 839 de 28 de septiembre de 1978 la Asamblea Parlamentaria del CdE recomienda al Comité de Ministros que al aplicar y revisar la. Carta Social tome en consideración las propuestas siguientes: i. Intensificar las actividades de informa- 
han influido en la extensión del catálogo de derechos sociales que reconoce la CSER, la que además de reunir en un instrumento todos los derechos contemplados en la Carta originaria y en sus protocolos, adiciona los siguientes derechos: derecho la protección en caso de despido (artículo 24); el derecho de los trabajadores a la tutela de sus créditos en caso de insolvencia del

ción, para que todos los interesados conozcan el contenido de la CSE; ii. Incitar la ratificación de la CSE por parte de los Estados miembros que todavía no han ratificado este instrumento, así como propiciar que, en plazos razonables, los Estados Miembros acepten el mayor número posible de disposiciones de la CSE; iii. La actualización del contenido de los derechos contenidos en la Parte II de la CSE. Las reformas propuestas por la Asamblea fueron las siguientes: Exigir a los Estados miembros, la aplicación de una política de empleo activa, y asegurando a todo trabajador real o potencial una adecuada protección contra el desempleo y sus consecuencias (artículo 1); en materia de contratación, promoción, despido y traslado erradicar cualquier diferencia entre trabajadores y trabajadoras e incrementar a un mínimo de cuatro semanas las vacaciones anuales pagadas (artículo 2); la necesidad de un ambiente de trabajo acorde con la naturaleza del trabajo, el desarrollo social y técnico de la sociedad (artículo 3); reforzar el derecho de huelga de los trabajadores y la supresión del derecho de los patronos a acciones colectivas (artículo 6), la inclusión de controles médicos periódicos; el incremento de la duración de la licencia por maternidad y su financiamiento con fondos público; iv. Tratándose de los inmigrantes, la Asamblea recomienda la inclusión en la CSE del derecho a la instrucción en el idioma del país de acogida y, en lo posible, el derecho de voto en las elecciones locales, además de la aplicación por parte de los Estados Miembros, de las disposiciones de la Convención Europea relativa al estatuto jurídico de los trabajadores migrantes, en la medida en que tales disposiciones aseguren una protección mejor que la prevista en la CSE; v. La inclusión de los siguientes derechos: el derecho a una seguridad social de base, el derecho a una pensión de vejez; el derecho a asegurar a las personas disminuidas el adecuado acondicionamiento de sus puestos de trabajo; el derecho de los trabajadores a participar en el proceso de adopción de decisiones en las empresas; el derecho a estar informados de la situación, finanzas y planificación futura de la empresa en que trabajan; el derecho de los trabajadores a participar en las decisiones relativas a las condiciones de trabajo; la protección de los trabajadores contra los efectos de la racionalización y de la introducción de tecnologías nuevas; el derecho de los hombres y de las mujeres a la igualdad de oportunidades y de trato en todas las esferas económicas, sociales y culturales; el derecho a la instrucción, y en particular a una instrucción básica, el derecho a licencia de estudios; el derecho a un alojamiento decente; el derecho de los trabajadores fronterizos a una protección social y económica adecuada, así como a una protección contra la discriminación en materia fiscal; el derecho de las personas de edad avanzada a una protección económica y social, además del derecho de las categorías menos favorecidas de la población a una protección social y económica reforzada; vi. Habida cuenta de la inclusión de nuevos derechos y de la modificación de las normas actuales, en consecuencia, la Asamblea propuso aumentar el número de obligaciones mínimas consignadas en la CSE, y vii. La revisión de los mecanismos de control establecidos en la CSE. Concretamente lo relativo a la aceleración del procedimiento de control de informes; el mejoramiento del formulario utilizado como base para la preparación de los informes bienales y el fortalecimiento de la función de los órganos que intervienen en el proceso de control. Asamblea Parlamentaria del Consejo de Europa, Recomendación 839 de 28 de septiembre de 1978, [Consulta: 1 de octubre de 2018], disponible en <https://digitallibrary.un.org/record/6650/files/E_CN.4_1333-ES.pdf> 
empresario (artículo 25); el derecho a la dignidad en el trabajo (artículo 26); el derecho de los trabajadores con cargas familiares a la igualdad de oportunidades y de trato (artículo 27); el derecho de los representantes de los trabajadores a la protección en el lugar de trabajo y a la concesión de facilidades apropiadas para desempeñar sus funciones (artículo 28); el derecho a la información y a la consulta en caso de despidos colectivos (artículo 29); el derecho a la protección contra la pobreza y la exclusión social (artículo 30) y el derecho a la vivienda (artículo 31).

La Carta Revisada -destinada a sustituir de forma progresiva a la CSE de $1961^{13}$ es invocada en el Tratado de Ámsterdam, de 2 de octubre de 1997, por lo que puede servir como orientación en la actividad de los órganos comunitarios de la UE. Cabe mencionar que la Asamblea Parlamentaria del CdE al considerar a la CSER como el estándar de derechos sociales más completo en Europa ha promovido su firma y ratificación.

A pesar de su revisión, el sistema de ratificación de la Carta de 1996 presenta una alta variabilidad, debido a que los Estados no están obligados a comprometerse en la realización de todos los derechos enunciados ${ }^{14}$. Se deben aceptar al menos seis de los nueve artículos de la parte II de la Carta, esto es, los artículos 1 (derecho al trabajo), 5 (derecho sindical), 6 (derecho a la negociación colectiva), 7 (derecho de los niños y adolescentes a protección), 12 (derecho a la seguridad social), 13 (derecho a la asistencia social y médica), 16 (derecho de la familia a una protección social, jurídica o económica), 19 (derechos de los trabajadores migrantes y sus familias a la protección y a la asistencia) y 20 (derecho a la igualdad de oportunidades y de trato en materia de empleo y de profesión sin discriminación por razón de sexo.

Las anteriores disposiciones retoman, con algunas adiciones, el denominado núcleo duro de la Carta originaria. Asimismo, el número total de artículos aceptados no debe ser inferior a dieciséis y el número total de párrafos no debe ser inferior a sesenta y tres.

Esta modalidad de ratificación, que da lugar a que no todos los Estados estén obligados por los mismos preceptos, si bien es flexible, constituye uno de los principales obstáculos por los que la Unión Europea ha dudado en adherirse a la CSE y reconocerla como parte del Derecho de la Unión, tal y como acontece con el Convenio Europeo de Protección de los Derechos Humanos y de las Libertades ${ }^{15}$.

${ }_{13}$ Artículo B de la Carta Social Europea Revisada, [Consulta: 11 de agosto de 2018], disponible en $<$ http://rm.coe.int/168047e013>

${ }^{14}$ Artículos 20 y 33 de la Carta Social Europea, op. cit., nota 3.

15 Artículo 6.3 del Tratado de la Unión Europea (versión consolidada), [Consulta: 22 de septiembre de 2018], disponible en $<$ http://eur-lex.europa.eu/resource.html?uri=cellar: 2bf140bf-a3f8-4ab2-b506-fd71826e6da6.0005.02/DOC_1\&format=PDF> 


\section{EL SISTEMA DE INFORMES Y EL DERECHO A LA SEGURIDAD SOCIAL}

Desde el año 2000 el Comité de Expertos Independientes cambió su nombre por el de Comité Europeo de Derechos Sociales (CEDS). A pesar de que el Comité, no tiene carácter jurisdiccional, es la instancia encargada de la interpretación, defensa y control de la CSE, sus protocolos y la CSER a través del procedimiento de informes que presentan los gobiernos y el sistema de reclamaciones colectivas.

El sistema de informes o sistema de información se estableció en la Parte IV de la CSE de 1961, pero desde 2006 el Comité de Ministros del CdE dividió las disposiciones de la Carta originaria y de la CSER en las siguientes áreas temáticas:

- Grupo 1. Empleo, formación e igualdad de oportunidades: artículos 1, 9, 10, 15, 18, 20, 24, 25.

- Grupo 2. Salud, seguridad social y protección social: artículos 3, 11, $12,13,14,23,30$.

- Grupo 3. Derechos laborales: artículos 2, 4, 5, 6, 21, 26, 28, 29.

- Grupo 4. Niños, familias, migrantes: artículos 7, 8, 16, 17, 19, 27, 31.4.

Conforme a la anterior división, los Estados miembros de la Carta informarán de forma anual al CEDS (el 31 de octubre) ${ }^{16}$ sobre la aplicación del grupo temático que corresponda a ese año de los cuatro grupos en que se clasifica la CSE. En consecuencia, cada disposición de la CSE al ser revisada una vez cada cuatro años, tal y como lo apunta Jimena Quezada, carece de una importante fuerza de reacción ante situaciones nacionales que merecerían una respuesta más rápida en términos de justicia social, pues en el intervalo de cuatro años entre informe e informe referente a cada grupo temático, es posible que se hayan producido cambios normativos o jurisprudenciales internos, con conclusiones tardías del CEDS ${ }^{17}$.

La otra gran debilidad del mecanismo de informes es la falta de información suficiente suministrada por los Estados miembros. Es necesario que los informes que proporcionen los Estados miembros contengan toda la información pertinente sobre las medidas adoptadas para garantizar la aplicación de cada disposición de la CSE o de la CSER.

${ }^{16}$ El nuevo sistema entró en vigencia a partir del 31 de octubre de 2007.

17 Luis Jimena Quezada, «Crónica de la Jurisprudencia del Comité Europeo de Derechos Sociales-2012», Revista Europea de Derechos Fundamentales, n. ${ }^{\circ} 20 / 2^{\circ}$, Semestre 2012, 364 . 
En lo particular, los informes deberán mencionar el marco legal (las leyes, reglamentos, convenios colectivos, jurisprudencia nacional, las decisiones pertinentes de los tribunales y otros órganos judiciales) y las medidas adoptadas para implementar el marco legal (disposiciones administrativas, programas, planes de acción, proyectos, etc.), las razones y alcance de las reformas, además de sus ámbitos de validez - personal, territorial, espacial y temporal-, cifras, estadísticas, la duración de los requisitos de residencia cuando corresponda, o cualquier otra información que permita una evaluación del grado en que se aplican las disposiciones normativas de la CSE. En el caso del numeral $12 \S 4$ de la CSE es necesario que los informes contengan la lista completa de los acuerdos bilaterales y multilaterales suscritos o cualquier otro medio propuesto o adoptado.

Toda la documentación que se aporte se examina durante el año siguiente por el CEDS, quien dicta una conclusión en la que decide la conformidad o no del país a la CSE o a la CSER, según sea el caso. Una vez que se hacen públicas las conclusiones, se transmiten al Comité Gubernamental -órgano compuesto por un representante de los gobiernos de cada una de las Partes contratantes- para que supervise el cumplimiento de las conclusiones del CEDS.

En caso de incumplimiento del Estado a las conclusiones, el Comité Gubernamental procederá a la elaboración de un informe que será tomado en consideración por el Comité de Ministros del CdE para emitir, por una mayoría cualificada de dos tercios de sus miembros, una recomendación en la que solicite al Estado miembro que modifique y adapte su normativa a los dictados de la CSE o de la CSER.

Al hacer la valoración de los informes que se presentan por los Estados, el CEDS hace una interpretación técnica autorizada de las distintas disposiciones de la Carta originaria y de la CSER, lo que provoca que se delimite su alcance y se les dote de un significado especifico. En el punto doce de la primera parte de la CSE y de la CSER se dispone que todos los trabajadores y las personas a su cargo tienen derecho a la seguridad social.

A pesar de que cada país es libre de definir su propio sistema de seguridad social, la CSE y la CSER imponen un conjunto de normas mínimas comunes para garantizar el ejercicio efectivo del derecho a la seguridad social. En lo particular, en los artículos $12 \S 1$ de la CSE y de la CSER se consigna el derecho de todas las personas a la seguridad social, por lo que corresponde a los Estados la obligación de garantizar este derecho mediante la existencia de un sistema de seguridad social que se reglamente en la ley y funcione en la práctica. De acuerdo con el CEDS para que se constituya un sistema de seguridad social en el sentido del artículo $12 \S 1$ de la CSE, es necesario que se cumplan las siguientes condiciones: 
- Que el sistema de seguridad social cubra los siguientes beneficios: atención médica, prestaciones de enfermedad, desempleo, vejez, accidentes de trabajo, maternidad, invalidez y sobrevivientes ${ }^{18}$.

- El sistema de seguridad social debe financiarse de forma colectiva, lo que significa que las contribuciones deben ser realizadas por los operarios, empleadores y el presupuesto del Estado ${ }^{19}$.

- El sistema de seguridad social debe cubrir un porcentaje significativo de la población por lo que hace al seguro de enfermedad y prestaciones familiares, y a su vez, amparar a un porcentaje de la población activa en materia de enfermedad, maternidad, beneficios de desempleo, pensiones, accidentes de trabajo y enfermedades profesionales ${ }^{20}$.

- Cuando el sistema se financia con impuestos, su cobertura en términos de personas protegidas debe basarse en el principio de no discriminación, sin perjuicio de las condiciones para la titularidad del derecho (prueba de medios, etc.) ${ }^{21}$.

Asimismo, el CEDS ha considerado que para dar cumplimiento al artículo $12 \S 1$ de la CSE, las prestaciones proporcionadas en las distintas ramas de la seguridad social deben ser adecuadas y, en particular, las prestaciones sustitutivas de los ingresos no deben ser tan bajas como para hacer que los beneficiarios caigan en la pobreza. La insuficiencia de un beneficio en una sola rama basta para provocar la no conformidad ${ }^{22}$ con las disposiciones de la CSE.

Lo anterior pone de manifiesto que no basta con la existencia de un sistema de seguridad social, sino que las prestaciones provistas dentro de las diferentes ramas de la seguridad social deben ser adecuadas. En este sentido,

18 Conclusiones 2013, Georgia, artículo 12§1, [Consulta: 29 de agosto de 2018], disponible en <http://hudoc.esc.coe.int/eng/\#\{“fulltext":[“,Georgia,artícle12"],"ESCDcTyp e":[“FOND”,"Conclusion","Ob”],"ESCDcIdentifier":[“2013/def/GEO/12/3/EN"] \}> y Conclusiones 2004, Bulgaria, artículo 12.1, [Consulta: 2 de octubre de 2018], disponible en <http://hudoc.esc.coe.int/eng/\# \{“fulltext":["conclusionsbulgaria"],"ESCDcType":[" FOND”,"Conclusion","Ob"],"ESCDcIdentifier":[“2004/def/BGR/12/1/EN"]\}\}>

${ }_{19}$ Conclusiones XVI, Observación interpretativa, artículo $12 \S 1,12 \S 2$ y $12 \S 3$, [Consulta: 29 de agosto de 2018], disponible en $<\mathrm{http}$ //hudoc.esc.coe.int/eng/\# \{“fulltext":["XVI1,"], "ESCDcType":[“FOND”,"Conclusion",,'Ob”],"ESCDcIdentifier":[“XVI-1_035_04/Ob/ FR']>

20 Idem.

${ }^{21}$ Conclusiones XVI-1, Statement of Interpretation on article 12, [Consulta: 26 de septiembre de 2018], disponible en $<$ http://hudoc.esc.coe.int/eng/\# \{ "fulltext"["ConclusionXVI1”],'ESCDcIdentifier":[“XVI-1_035_04/Ob/FR"],'ESCDcType”:[“FOND”,'Conclusion” ,"Ob"] $>$

${ }^{22}$ Conclusiones 2006, Portugal, [Consulta: 30 de septiembre de 2018], disponible en $<$ http://hudoc.esc.coe.int/eng/\# \{“fulltext”:[“conclusionportugal2006”],"ESCDcType”:[“ FOND”,"Conclusion","Ob”],"ESCDcIdentifier”:[“2006/def/PRT/12/1/FR”]\}> 
cuando se trata de beneficios de reemplazo de ingresos, su nivel debe situarse entre el $40 \%$ y el $50 \%$ de la mediana de los ingresos equivalentes. Cuando el nivel del beneficio originalmente cae por debajo del $40 \%$ del ingreso medio equivalente, es manifiestamente inadecuado, sin que la agregación de otros beneficios genere la conformidad con el artículo $12 \S 1$ de la CSE ${ }^{23}$.

Sólo cuando un beneficio de sustitución de ingresos se encuentre entre el $40 \%$ y el $50 \%$ del ingreso medio equivalente, se podrá tener en cuenta otros beneficios suplementarios, como la asistencia social y los subsidios de vivienda, según corresponda ${ }^{24}$.

En lo concerniente al artículo $12 \S 1$ de la CSER, el Comité dispone que cuando se trata de prestaciones de sustitución de ingresos, su nivel debe fijarse de manera que guarde una proporción razonable con los ingresos anteriores y nunca debe caer por debajo del umbral de pobreza definido como el $50 \%$ del ingreso medio equivalente calculado sobre la base del valor umbral de Eurostat en riesgo de pobreza ${ }^{25}$.

Por lo que respecta al recurso a las prestaciones complementarias, el CEDS ha establecido que corresponde a los Estados Partes demostrar que este tipo de prestaciones se proporcionan efectivamente a todas las personas afectadas por las prestaciones de la seguridad social por debajo del umbral del 50\%. Empero, la dependencia de los beneficios suplementarios de carácter de asistencia social no debe transformar al sistema de seguridad social en un sistema básico de asistencia social ${ }^{26}$.

Los anteriores requerimientos obedecen a que conforme al artículo $12 \S 2$ de la CSE, los Estados miembros deben mantener un régimen de seguridad social en un nivel satisfactorio, equivalente, por lo menos, al exigido para la ratificación del Convenio Internacional del Trabajo (número 102) sobre normas mínimas de seguridad social. En el artículo $12 \S 2$ de la CSER se dispone que el régimen de seguridad social debe cumplir con un nivel equivalente, por lo menos, al exigido para la ratificación del Código Europeo de Seguridad Social.

Ante la ratificación del Código Europeo de Seguridad Social, el incumplimiento de este instrumento dará lugar a una conclusión de no conformidad

${ }^{23}$ Conclusiones XVIII-1, Austria, [Consulta: 30 de agosto de 2018], disponible en $<$ http://hudoc.esc.coe.int/eng/\#\{“ESCDcIdentifier":[“XVIII-1/def/AUT/12/1/EN"]\}> y Conclusiones 2013, Finlandia, artículo $12 \S 1$ [Consulta: 30 de agosto de 2018], disponible en $<$ http://hudoc.esc.coe.int/eng/?i=2013/def/FIN/12/1/FR $\}>$

${ }^{24}$ Conclusiones 2013, Hungría, artículo 12\$1, [Consulta: 30 de agosto de 2018], disponible en $<$ http://hudoc.esc.coe.int/eng/\# \{“fulltext":[“conclusio2013hungary"],"ESCDcIden tifier":[“2013/def/HUN/12/1/EN”],"ESCDcType":[“FOND”,"Conclusion”,,'Ob”]\}>

${ }_{25}$ Conclusiones 2006, Portugal, op. cit., nota 22.

${ }^{26}$ Conclusiones XVI-1, Statement of Interpretation on article 12, op. cit., nota 21. 
con el artículo $12 \S 2$ de la CSER. Empero, cuando el Estado en cuestión no ha ratificado el Código Europeo de Seguridad Social, el CEDS realiza su propia evaluación del sistema de seguridad social para decidir sobre la conformidad con el referido artículo $12 \S 2^{27}$.

En lo concerniente a los artículos $12 \S 3$ de la CSE y de la CSER se consagra la obligación de las Partes contratantes de esforzarse por elevar de forma progresiva el sistema de seguridad social a un nivel superior. Puede darse el caso que la evolución positiva del sistema de seguridad social sea conforme a lo dispuesto en los artículos $12 \S 3$ de la CSE y de la CSER, incluso si el sistema de seguridad social no ha alcanzado los niveles requeridos en los dos primeros párrafos de los artículos 12 de ambos instrumentos normativos.

La expansión de esquemas, la protección contra nuevos riesgos y el aumento de las tasas de beneficios ${ }^{28}$, son ejemplos representativos de la mejora en los sistemas de seguridad social tendientes a cumplimentar los artículos $12 \S 3$ de la CSE y de la CSER, cuyo carácter dinámico (reconocido por el CEDS desde sus primeras conclusiones ${ }^{29}$ obedece a la posibilidad de aceptar modificaciones en los sistemas de seguridad social, siempre que se tomen en consideración los siguientes requerimientos:

- La naturaleza de los cambios. Todo cambio en un sistema de seguridad social debe garantizar el mantenimiento de un sistema básico de seguridad social obligatorio que sea lo suficientemente extenso ${ }^{30}$ (ámbito de aplicación, condiciones de concesión de derechos de emisión, importes de la prestación y plazos).

- Las razones dadas para los cambios (objetivos perseguidos) y el marco de la política social y económica de la que se derivan ${ }^{31}$.

- El contenido de los cambios introducidos (alcance, condiciones para otorgar el beneficio, nivel del beneficio, períodos, etc. $)^{32}$. Ninguna modificación debe socavar la protección social efectiva de todos los miembros de la sociedad contra los riesgos sociales y económicos ${ }^{33}$ o excluir

${ }^{27}$ Conclusiones XIV-1, Finland, [Consulta: 2 de octubre de 2018], disponible en $<$ http: //hudoc.esc.coe.int/eng/\# \{“fulltext":["ConclusionsXIV-1,Finland"],"ESCDcIdenti fier":[“XIV-1/def/FIN/12/2/EN"],"ESCDcType":["FOND”,"Conclusion","Ob”] \}>

${ }_{28}$ Conclusiones XVI-1, Statement of Interpretation on article 12, op. cit., nota 21.

29 Conclusiones I, Statement of Interpretation on Article 12.3, [Consulta: 29 de septiembre de 2018], disponible en < http://hudoc.esc.coe.int/eng/\#\{“fulltext":["i"],"ESCDc Type":[“FOND”,'Conclusion",,'Ob”],'ESCDcIdentifier":[“I_Ob_-45/Ob/EN"]\}>

${ }^{30}$ Conclusiones XVI-1, Statement of Interpretation on article 12, op cit., nota 21.

${ }^{31}$ Conclusiones XVI, Observación interpretativa, artículo $12 \S 1,12 \S 2$ y $12 \S 3$, op. cit., nota 19.

32 Idem.

${ }^{33}$ Conclusiones XVI-1, Statement of Interpretation on article 12, op. cit., nota 21. 
categorías enteras de trabajadores de la protección social ofrecida por el sistema de seguridad social ${ }^{34}$ (categorías y número de personas afectadas, niveles de derechos de emisión antes y después de la alteración).

- La necesidad o importancia de la reforma (las categorías y el número de personas afectadas, la cantidad de beneficios antes y después de la modificación) y su adecuación en la situación que ha dado lugar a estos cambios $^{35}$.

- La existencia de medidas de asistencia social para los que se encuentren en situación de necesidad como consecuencia de las modificaciones introducidas ${ }^{36}$.

- La expresión de los resultados que se obtengan con los cambios ${ }^{37}$.

- Todo cambio en un sistema de seguridad social debe garantizar el mantenimiento de un sistema básico de seguridad social obligatorio que sea lo suficientemente extensivo ${ }^{38}$.

- Las modificaciones no deben transformar el sistema de seguridad social en un sistema básico de asistencia social ${ }^{39}$.

- Que las restricciones o limitaciones a los derechos en el ámbito de la seguridad social sean justificadas y compatibles con la CSE y la CSER en la medida en que sean necesarias para garantizar el mantenimiento de un determinado sistema de seguridad social ${ }^{40}$.

- No puede ser un elemento a valorar en las restricciones de los derechos las crisis económicas de un país.

Las medidas que no respetan estos límites no pueden considerarse conformes con los artículos $12 \S 3$ de la CSE o de la CSER.

De acuerdo con los anteriores criterios, al igual que en el Sistema Universal de Derechos Humanos ${ }^{41}$, el CEDS ha determinado que en tiempos de cri-

${ }^{34}$ Idem.

35 Conclusiones XVI, Observación interpretativa, articulo $12 \S 1,12 \S 2$ y $12 \S 3$, op. cit., nota 19.

${ }^{36}$ Conclusiones XIII-4 Observación interpretativa articulo 12§3, [Consulta: 24 de septiembre de 2018], disponible en <http://hudoc.esc.coe.int/eng/\#\{ "fulltext":["Conclusi onXIII4"],"ESCDcType":[“FOND”,"Conclsion",,Ob”],"ESCDcIdentifier":[“XIII-4 $\mathrm{Ob}-2 / \mathrm{Ob} / \mathrm{FR}$ '] $\}>$

${ }^{37}$ Conclusiones XVI, Observación interpretativa articulo $12 \S 1,12 \S 2$ y $12 \S 3$, op. cit., nota 19.

${ }^{38}$ Conclusiones XVI-1, Statement of Interpretation on article 12, op. cit., nota 21.

${ }^{39}$ Idem.

${ }^{40}$ Conclusiones XIII-4, Statement of Interpretation on article 12\$3, [Consulta: 30 de septiembre de 2018], <http://hudoc.esc.coe.int/eng/\#\{“fulltext":[“ConclusionXIII4”],"ESC DcType":["FOND",'Conclusion"”'Ob"],"ESCDcIdentifier":[“XIII-4_Ob_-2/Ob/FR"]\}>

${ }^{41}$ El Comité de Derechos Económicos, Sociales y Culturales ha sostenido que los poderes públicos tienen el deber de asegurar, en todo momento e incluso en épocas de 
sis económica no debe existir una reducción en la protección de los derechos reconocidos por la CSE y la CSER. Por el contrario, los gobiernos deben adoptar todas las medidas necesarias para conseguir que los derechos sean efectivamente garantizados en el momento en el que la necesidad de protección se hace sentir más ${ }^{42}$.

Por último, para garantizar el respeto y acceso al derecho a la seguridad social de las personas que se desplazan entre Estados, los artículos $12 \S 4$ de la CSE y de la CSER imponen a las partes contratantes ${ }^{43}$ la obligación de adoptar medidas unilaterales, legislativas, administrativas, acuerdos bilaterales y multilaterales apropiados para que sin perjuicio de las condiciones establecidas, se garantice la igualdad de trato entre los nacionales de cada una de las partes contratantes y los de las demás partes en lo relativo a los derechos de seguridad social. Por supuesto, que lo anterior requiere que los Estados eliminen todas las formas de discriminación de su legislación de seguridad social contra los extranjeros.

crisis, al menos el contenido esencial de los derechos, lo que ha abierto camino para el cumplimiento de las obligaciones a cargo del Estado en materia de derechos sociales.

${ }_{42}$ Introducción general a las Conclusiones XIX-2, 2009, [Consulta: 11 de septiembre de 2018], <http://hudoc.esc.coe.int/eng/\# \{“fulltext":["SOCIALSECURITY"],"ESCDcType":["FOND”,"Conclusion","Ob”],"ESCDcIdentifier":[“cc-XIX-2,2009dmerits-en"\}>; Reclamación 76/2012 Federación de Pensionistas Asalariados de Grecia (IKA-ETAM) vs. Grecia, [Consulta: 11 de septiembre de 2018], <http://hudoc.esc.coe. int/eng/\# ‘“fulltext”:[“SOCIALSECURITY”],"ESCDcType":[“FOND”,"Conclusion",", Ob"],"ESCDcIdentifier":[“cc-78-2012-dmerits-en”]>; Reclamación 77/2012, Federación Panhelénica de Pensionistas de la Servicio Público (POPS) vs. Grecia [Consulta: 11 de septiembre de 2018], <http://hudoc.esc.coe.int/eng/\# \{"fulltext":["SOCIALSECURI TY”],"ESCDcType”:[“FOND”,"Conclusion","Ob”],"ESCDcIdentifier":[“cc-77-2012dmerits-en"] $\}>$ Reclamación 78/2012, interpuesta por el Sindicato de Pensionistas del Personal Ferroviario de Atenas-Piraeus (ISAP) vs. Grecia, [Consulta: 11 de septiembre de 2018],<http://hudoc.esc.coe.int/eng/\# " fulltext":["SOCIALSECURITY"],"ESCDcType"'FOND","Conclusion","Ob”],"ESCDcIdentifier":[“cc-78-2012-dmeritsen"]\}>; Reclamación 79/2012, Federación Panhelénica de Pensionistas de la Empresa Pública de Electricidad vs. Grecia, Consulta: 11 de septiembre de 2018], <http://hudoc. esc.coe.int/eng/\# \{“fulltext”:[“SOCIALSECURITY"],"ESCDcType"'FOND”,"Conclusi on","Ob"],"ESCDcIdentifier":[“cc-79-2012-dmerits-en"]\}> y Reclamación 80/2012, Sindicato de Pensionistas del Banco Agrícola de Grecia (ATE) vs. Grecia, [Consulta: 11 de septiembre de 2018], <http://hudoc.esc.coe.int/eng/\#\{“fulltext”:["SOCIALSECURI TY"],"ESCDcType"'FOND”,"Conclusion","Ob”],"ESCDcIdentifier":[“cc-80-2012dmerits-en'] $\}>$

${ }^{43}$ El alcance del Artículo $12 \S 4$ se extiende a los trabajadores por cuenta propia, en comisión de servicios, los refugiados y los apátridas. Vid. Conclusions XIV-1, Turkey, article 12§4, [Consulta: 6 de octubre de 2018], <http://hudoc.esc.coe.int/eng/\#("fulltext": ["ConclusionsXIV-1,Turkey"],"ESCDcIdentifier":["XIV-1defTUR/12/4EN"],"ESCDcT ype":[“FOND","Conclusion","Ob"] $\}>$ 
Por consecuencia, al no encontrarse garantizada la igualdad de trato en la recepción de las prestaciones de seguridad social se contraviene los artículos $12 \S 4$ de la CSE y de la CSER. Además, conforme a los referidos artículos $12 \S 4$, en ningún caso, se justifica que la legislación nacional pueda reservar un beneficio de seguridad social de forma exclusiva para los nacionales o imponer condiciones adicionales o más restrictivas para los extranjeros.

De igual manera en la legislación nacional tampoco se puede estipular criterios de elegibilidad para beneficios de seguridad social que, aunque se aplican sin referencia a la nacionalidad, son más difíciles de cumplir para los extranjeros y, por lo tanto, los afectan en mayor medida ${ }^{44}$. Sin embargo, la legislación puede requerir que se complete un período de residencia para las prestaciones no contributivas. A este respecto, los artículos $12 \S 4$ de la CSE y de la CSER exigen que cualquier período de residencia sea razonable ${ }^{45}$ (residencia no excesiva).El CEDS ha calificado de excesiva la exigencia de diez años de residencia para acceder a una pensión de jubilación.

Por disposición de los artículos $12 \S 4$ de la CSE y de la CSER, los otros principios que han de observarse y respetarse son la conservación de los derechos adquiridos, sean cuales fueren los desplazamientos que las personas protegidas pudieren efectuar entre los territorios de las partes contratantes; así como la concesión o derecho a la retención de mayores derechos mediante la agregación de empleo o períodos de seguro completados en el extranjero; el mantenimiento y el restablecimiento de los derechos de seguridad social, por medios tales como la totalización de los períodos de seguro, empleo o residencia completados de conformidad con el marco legal de cada una de las partes contratantes.

\section{EL PROCEDIMIENTO DE RECLAMACIONES COLECTIVAS Y EL DERECHO A LA SEGURIDAD SOCIAL}

De acuerdo con el preámbulo del Protocolo Adicional a la CSE de 9 de noviembre de 1995, la instauración del procedimiento de reclamaciones colectivas obedece a la necesidad de mejorar la aplicación efectiva de los derechos sociales garantizados por la CSE y reforzar la participación de los empresarios, trabajadores, así como de las organizaciones no gubernamentales ${ }^{46}$. Las principales características del procedimiento de reclamaciones colectivas son las siguientes:

${ }^{44}$ Conclusiones XIII-4, Statement of Interpretation on article 12, op. cit., nota 40.

45 Conclusiones 2004, Lithuania, article 12-4, [Consulta: 9 de octubre de 2018], $<$ http://hudoc.esc.coe.int/eng/\# \{“fulltext":["Conclusions2004,Lithuania"],"ESCDcIdenti fier”:[“2004/def/LTU/12/4/EN"],"ESCDcType":[“FOND”,"Conclusion","Ob”]\}>

46 Preámbulo del Protocolo Adicional a la Carta Social Europea que prevé un sistema de reclamaciones colectivas, adoptado por el Comité de Ministros del Consejo de Europa 
- Este mecanismo se aplica solamente a los Estados partes del Protocolo de 1995 de la CSE.

- Las quejas pueden interponerse sin que se hayan agotado los recursos nacionales y sin que la organización querellante haya sido necesariamente víctima de la violación.

- La interposición de la reclamación colectiva puede tener un carácter preventivo, debido a que puede interponerse para que se dictamine sobre la conformidad o no de una norma o práctica con la CSE o la CSER.

Durante la sesión 1196 del Comité de Ministros celebrada los días 2 y 3 de abril de 2014 se determinó que los Estados que han aceptado el procedimiento de reclamaciones colectivas sólo están obligados a presentar un informe simplificado cada dos años para evitar las fluctuaciones excesivas en la carga de trabajo del CEDS y hacer más operativo y simplificado el sistema de informes para los Estados que hayan aceptado el Protocolo de 1995.

Las organizaciones que están legitimadas para presentar reclamaciones colectivas son los interlocutores sociales europeos, como la Confederación Europea de Sindicatos (CES) en nombre de trabajadores; el Business Europe (anteriormente UNICE) y la Organización Internacional de Empleadores (IOE) en nombre de los empleadores, además de las organizaciones no gubernamentales dotadas de estatuto consultivo ante el $\mathrm{CdE}^{47}$, cuya solicitud sea aceptada por el Comité Gubernamental, y los interlocutores sociales a nivel nacional. El Protocolo de 1995 establece que cualquier Estado contratante podrá reconocer el derecho de representación a organizaciones no gubernamentales $(\mathrm{ONG})$ nacionales dentro de su jurisdicción para que puedan presentar quejas colectivas ${ }^{48}$.

el 22 de junio de 1995 y abierto a la firma 9 de noviembre de 1995. Protocolo Adicional a la Carta Social Europea de 1995, [Consulta: 9 de octubre de 2018], <http://www.juntadeandalucia.es/empleo/anexos/ccarl/22671.pdf>

${ }^{47}$ En julio de 2016, el Comité de Ministros adoptó la Resolución (2016) 3 sobre el estado participativo. Este ordenamiento establece las reglas para la concesión de estatus participativo a las ONG internacionales, brinda más información sobre los antecedentes del Estado, las condiciones que deben cumplir las ONG internacionales y las posibilidades que brinda a las ONG internacionales de cooperar con el Consejo de las OING. Europa. En la actualidad, 288 OING tienen un estatus participativo. Las ONG internacionales que gozan de un estatus participativo forman la Conferencia de ONG, quien representa a la sociedad civil en el Consejo de Europa y trabaja para promover la democracia participativa. Además de celebrar dos sesiones anuales al año, organiza eventos vinculados a las prioridades del Consejo de Europa.

${ }^{48}$ Hasta ahora solo Finlandia ha otorgado a las organizaciones no gubernamentales nacionales representativas dentro de su jurisdicción, el derecho a presentar quejas en su 
Toda reclamación colectiva deberá presentarse por escrito en uno de los idiomas oficiales del CdE (inglés o francés) con la referencia al precepto o preceptos de la CSE o de la CSER aceptado/s y en qué medida se inobserva por el Estado. Al turnarse la reclamación colectiva al CEDS se pronunciará, en un principio, sobre su admisibilidad o no.

En tanto que al Estado en cuestión se le pide en primer lugar que presente por escrito observaciones respecto de la admisibilidad a trámite de la queja ${ }^{49}$. El reclamante puede entonces ser invitado a contestar a las observaciones presentadas por el Estado. Sin embargo, el CEDS puede decidir también no hacer partícipes al Estado y al reclamante cuando la admisión o inadmisibilidad a trámite de la queja interpuesta sea notoria. La decisión sobre la admisión a trámite se publica en el sitio web del CEDS.

Una vez decretada la admisibilidad de la reclamación, el CEDS puede solicitar a las partes las aclaraciones, informaciones u observaciones escritas que procedan, así como organizar una audiencia con sus representantes ${ }^{50}$. Existe la posibilidad de que, de oficio o a instancia de parte, se adopten de forma excepcional medidas inmediatas, con el propósito de evitar que se produzca un grave daño irreparable y con la finalidad de asegurar el respeto efectivo de los derechos reconocidos en la CSE y en la CSER.

Finalmente, el CEDS deberá adoptar una decisión sobre el fondo de la reclamación. Esta decisión incluye los motivos considerados, y puede que también las opiniones discrepantes. Las decisiones se transmiten entonces al Comité de Ministros del CdE, quien aprobará la resolución basada en la decisión del CEDS. Cuando en la recomendación se determina que la normativa no es acorde con el articulado de la CSE o de la CSER se invita a la adopción de medidas al respecto, por lo que el Estado demandado deberá informar sobre las medidas seguidas para dar cumplimiento a la decisión del CEDS.

Debido a su naturaleza colectiva, las quejas solo pueden plantear problemas de inconformidad de la legislación o de la práctica de un Estado con las disposiciones de la CSE o de la CSER. La reclamación 88/2012 ${ }^{51}$ seguida por la Sociedad Finlandesa de Derechos Sociales en contra de Finlandia es a este respecto ilustrativa. Según el dicho de la organización querellante, el Estado

contra. Declaration contained in a letter from the President of Finland, dated 21 August 1998, registered at the Secretariat General on 26 August 1998. Or. Engl.

49 Artículo 4 del Protocolo Adicional a la Carta Social Europea que prevé un sistema de reclamaciones colectivas, op. cit., nota 46.

${ }^{50}$ Idem. Artículo 7.4 del Protocolo Adicional a la Carta Social Europea.

${ }^{51}$ Reclamación 88/2012, Sociedad Finlandesa de Derechos Sociales vs Finlandia, [Consulta:7deoctubrede2018],<http://hudoc.esc.coe.int/eng/\# \{“fulltext”:[“88/2012”],"ESCDcType":[“FOND”"“Conclusion","Ob"'],"'ESCDcIdentifier":[“cc-88-2012-dmeritsen'] $\}>$ 
finlandés no ha mantenido el sistema de seguridad social a un nivel satisfactorio ni ha elevado de manera progresiva el sistema a un nivel superior, en contravención a los numerales $12 \S 1,12 \S 2$ y $12 \S 3$ de la CSE.

El CEDS al analizar el caso observó que, en el caso de Finlandia, el 50\% de los ingresos medios equivalentes correspondían en 2013 a 970 euros por mes para una persona sola, y que el $40 \%$ de los ingresos medios equivalentes correspondían a 776 euros por mes durante ese mismo año. En tanto que la prestación mínima diaria de enfermedad en 2013 fue de 23,77€ a 59,4 euros mensuales, lo que era equivalente al $31 \%$ de la renta mediana equivalente.

Asimismo, el Comité observó que, después de aplicar el impuesto sobre la renta del $20 \%$, la prestación mínima de enfermedad por mes era de 475 euros mensuales, lo que representaba tan sólo el $24 \%$ de los ingresos medianos equivalentes que contrasta con el importe medio de la prestación de enfermedad pagada en 2012 que fue de 1.370 euros, que resulta superior al ingreso mediano equivalente en el año $2013^{52}$.

En lo concerniente a las prestaciones de maternidad y prestaciones de rehabilitación, el CEDS observó que el nivel de estas prestaciones fue el mismo que el beneficio por enfermedad y, por lo tanto, correspondía al $31 \%$ de la renta mediana equivalente antes de la aplicación de los impuestos y al $24 \%$ de la renta media equivalente después de impuestos ${ }^{53}$. Respecto del subsidio de desempleo básico al ubicarse en 32,46 euros al día en 2013 representó el $36 \%$ del ingreso mediano equivalente ${ }^{54}$. Al aplicar a esta última prestación los respectivos impuestos quedó en 558 euros mensuales en 2013, o sea, el $29 \%$ de los ingresos medianos equivalentes.

Por su parte, en el caso de la pensión de garantía al ubicarse en 738,82 euros en 2013, representó el 38\% de la renta mediana equivalente. Es a partir de las anteriores cifras que el CEDS observó que al situarse el nivel de las prestaciones de la seguridad social por debajo del $40 \%$ del ingreso mediano equivalente, resultaban inadecuadas en el sentido del artículo $12 \S 1$ de la CSE, por lo que el CEDS no consideró el posible impacto de otras prestaciones complementarias como las prestaciones de asistencia social y la asignación de vivienda.

Y, por lo que hace al artículo $12 \S 3$ de la CSE, el Comité hizo referencia al examen de la situación en Finlandia en el contexto del procedimiento de presentación de informes durante el período de 2008-2011. Después de tomar nota de una serie de mejoras realizadas en el ámbito de la seguridad social durante el período de referencia, el CEDS llegó a la conclusión de que la situación en Finlandia era conforme al artículo $12 \S 3$ de la CSE, sin que los

\footnotetext{
52 Idem. Reclamación 88/2012, párrafos 68 y 69

53 Idem. Reclamación 88/2012, párrafo 70.

${ }^{54}$ Idem. Reclamación 88/2012, párrafo 71
} 
argumentos aducidos en la reclamación interpuesta justifiquen que el Comité llegue a una conclusión diferente.

Por su parte, en la reclamación 66/2011 presentada el 21 de febrero de 2011 por la Federación General de Trabajadores de la Empresa Nacional de Electricidad (GENOP-DEI) y la Confederación de Funcionarios Públicos Griegos (ADEDY) contra Grecia ${ }^{55}$, ambos sindicatos reclamaron, por lo respecta al derecho de la seguridad social, que el artículo $74 \S 9$ de la Ley n. ${ }^{\circ} 3863 / 2010$ se limita a regular las prestaciones en especie por enfermedad, pero se excluye el reembolso de los gastos de prescripción, además de que la cobertura de la seguridad social contra los riesgos sociales y económicos que se otorgan a los menores que participan en contratos de aprendizaje especiales, a razón del 1\%, resulta limitada y rudimentaria.

En este caso el Comité consideró que las alegaciones de los querellantes, en su contenido, se relacionaban con el artículo $12 \S 3$ y no con el artículo $12 \S 2$ como originalmente sostenían ambas organizaciones. Asimismo, el CEDS estableció que al ser limitada la protección contra los riesgos sociales y económicos representaba un deterioro del esquema de seguridad social, por lo que se incumplía con los criterios establecidos para ser compatible con el artículo $12 \S 3$ de la CSE.

A pesar del exiguo número de Estados que han aceptado el Protocolo de 1995, hasta la fecha los principales casos resueltos tienen que ver con impacto negativo de las crisis financieras y económicas en el disfrute de los derechos sociales fundamentales en Europa. Lo anterior se evidencia con las reclamaciones 76/2012 $2^{56} ; 77 / 2012^{57}, 78 / 2012^{58} ; 79 / 2012^{59}$ y 80/2012 ${ }^{60}$ interpuestas en contra de las políticas de austeridad instauradas por el gobierno de Grecia al aprobar la Ley n. ${ }^{\circ} 3845$ de 6 de mayo de 2010; la Ley n. 3847 de 11 de mayo de 2010; la Ley n. ${ }^{\circ} 3863$ de 15 de julio 2010; la Ley n. ${ }^{\circ} 3865$ de 21 de julio de 2010; la Ley n. ${ }^{\circ} 3896$, de $1^{\circ}$ de julio de 2011 y la Ley n. ${ }^{\circ} 4024$, de 27 de octubre de 2011. Las anteriores disposiciones normativas contemplaron las siguientes medidas ${ }^{61}$ :

${ }^{55}$ Reclamación 66/2011 Federación General de Trabajadores de la Empresa Nacional de Electricidad (GENOP-DEI) y la Confederación de Funcionarios Públicos Griegos (ADEDY) contra Grecia [Consulta: 7 de octubre de 2018], $<$ http://hudoc.esc.coe.int/ eng/\#\{“ESCDcIdentifier":[“cc-66-2011-dmerits-en"] $\}>$. La queja fue registrada el 21 de febrero de 2011.

${ }^{56}$ Reclamación 76/2012, op. cit., nota 42

57 Reclamación 77/2012, op. cit., nota 42

58 Reclamación 78/2012, op. cit., nota 42

59 Reclamación 79/2012, op. cit., nota 42

${ }^{60}$ Reclamación 80/2012, op. cit., nota 42

${ }^{61} \mathrm{M}^{\mathrm{a}}$ Carmen SAlCEdo Beltrán, "Crisis económica, medidas laborales y vulneración de la Carta Social Europea", Revista Europea de Derechos Fundamentales (número 22/2, Semestre 2013) 120-121. 
- Recorte de las pensiones de base de los menores de cincuenta y cinco años en un $40 \%$ de la cifra que superaban los 1.000 euros, y para los que tenían esa edad o superior que cobraban una pensión por encima de 1.200 euros, la reducción aplicada fue la equivalente al 20\% de la cifra que superara esa cuantía. En el caso de jubilación anticipada, la reducción fue de un 50\% aproximadamente, y en el caso de pensionistas que cobraban dos pensiones, la reducción se aplicó en ambos beneficios.

- Disminución de las pensiones complementarias, conforme al sector y a la entidad aseguradora (caja) que las gestione. En concreto, respecto de las relacionadas con la función pública, se acordó que la reducción fuera del $20 \%$, y en el caso de que, después de aplicarla, la pensión restante superara los 500 euros, se disminuyó en un $50 \%$ más.

- Reducción o supresión de las primas de las festividades de Navidad y Pascua, así como las primas de vacaciones reconocidas para los pensionistas o los beneficiarios de asistencia social. En concreto se suprimieron para los que tenían una pensión mensual superior a 2.500 euros, y se dejaron en 400 euros las pagas de Navidad y en 200 euros las primas de Pascua y verano respecto de los que cobraban menos de esa cuantía.

- Creación de una contribución general obligatoria, denominada de solidaridad, imputable a los pensionistas que cobraban por encima de los 1400 euros, por lo que la aportación oscilaba entre el 3\% y el 14\%, sin que la cuantía de la pensión pudiera ser inferior, después de aplicar la deducción, al umbral señalado. De manera adicional se instauró una contribución complementaria a la anterior, para los pensionistas menores de sesenta años, cuyo porcentaje fluctuó entre el $6 \%$ (pensiones entre 1700 y 2300 euros) y el $10 \%$ (pensiones superiores o iguales a 2.900 euros).

- Suspensión o reducción de las pensiones en caso de ocupación, cuando los pensionistas menores de cincuenta y cinco años que ejercían una actividad profesional no pudieran recibir una pensión de jubilación principal o complementaria. De superar esa edad, podían cobrarla con una disminución del 70\% para asalariados no especializados y en un $50 \%$ para profesiones liberales y trabajadores independientes respecto de la cuantía que superaba en treinta días de salario.

- Disminución entre el 5\% y el 20\% de la prestación de solidaridad social para los pensionistas del sector privado ${ }^{62}$, además de la supresión o disminución de las prestaciones que se señalaron con anterioridad.

${ }^{62}$ Este beneficio consiste en un subsidio no contributivo destinado a los pensionistas que tienen muy pocos ingresos como consecuencia de cobrar unas pensiones de jubilación o invalidez muy bajas, siendo su cuantía entre 230 y 57,50 euros, dependiendo de los ingresos. 
Después de analizar las referidas reclamaciones colectivas, para el CEDS la crisis económica no debería generar la reducción de la protección de los derechos reconocidos por la CSE, quedando los gobiernos obligados a tomar todas las medidas necesarias para garantizar que los derechos de la Carta originaria estén efectivamente garantizados en un período de tiempo en el que los beneficiarios requieren de una mayor protección ${ }^{63}$. De acuerdo con el CEDS, el gobierno de Grecia no llevó a cabo el nivel mínimo de investigación y análisis sobre los efectos de medidas de alcance que son necesarias para evaluar de manera significativa su impacto total en los grupos vulnerables de la sociedad. Tampoco discutió los estudios disponibles con las organizaciones interesadas, a pesar de que representan los intereses de muchos de los grupos más afectados por las medidas en cuestión ${ }^{64}$.

El CEDS ha considerado que existen otros mecanismos que son más adecuados para abordar las denuncias relativas a los efectos de la legislación impugnada sobre el derecho de propiedad de los pensionistas, y toda vez que el gobierno helénico tampoco procuró, como lo exige el artículo $12 \S 3$ de la CSE, mantener un nivel de protección suficiente en beneficio de los miembros más vulnerables de la sociedad, el CEDS concluyó que, debido al efecto acumulativo de las medidas restrictivas y de los procedimientos adoptados para su puesta en práctica, contenidas en las disposiciones normativas, el gobierno helénico infringe los artículos $12 \S 3$ y $31 \S 1$ de la CSE al modificar los regímenes pensionarios públicos y privados.

Cabe mencionar que el 23 de agosto de 2017 se registró la queja colectiva 156/2017, interpuesta por la Asociación Panhelénica de Pensionados del Grupo OTE Telecomunicaciones en contra Grecia. La organización querellante alegó que las leyes 4336/2015, 4387/2016 y 4472/2017 implementadas por el Estado griego, que introdujeron la reducción de ciertas pensiones y asignaciones, fueron adoptadas en contravención al artículo 12 en sus párrafos segundo y tercero de la Carta originaria. La queja registrada el 23 de agosto de 2017, se desechó por inadmisible el 22 de marzo de 2018, porque el CEDS concluyó que se refería a la CSE de 1961 y al Protocolo Adicional de 1988, que al 23 de agosto de 2017 en se presentó la queja, no se encontraban vigentes para Grecia con motivo de la ratificación de la CSER el 18 de marzo de 2016 y su entrada en vigor el $1^{\circ}$ de mayo de 2016.

Importante también ha sido la justiciabilidad indirecta del derecho de la seguridad social a partir del principio de igualdad y la prohibición de toda discriminación basada en la raza, el color, el sexo, la lengua, la religión, las

\footnotetext{
${ }^{63}$ Reclamación 79/2012, párrafo 70, op. cit., nota 42.

${ }^{64}$ Reclamación 77/2012, párrafo 74, op. cit., nota 42.
} 
opiniones políticas o de otra naturaleza, la extracción u origen social, la salud, la pertenencia a una minoría nacional, el nacimiento o cualquier otra situación que atente contra la dignidad humana y tenga por objeto anular o menoscabar los derechos de las personas. En este supuesto es de destacarse la reclamación colectiva 102/2013 ${ }^{65}$ interpuesta por la Asociación Nacional de Magistrados de Paz (ANGdP) en contra de Italia.

La ANGdP refirió que la legislación italiana no prevé la protección de la seguridad social en favor de los juzgados de paz (giudici di pace), lo que es contrario a los artículos E y $12 \S 1$ de la CSE, al existir discriminación para esta categoría de jueces honorarios en comparación con los jueces titulares y otras categorías de jueces legos, quienes cuentan con un sistema de seguridad social.

En vista de las tareas asignadas y desempeñadas, así como a la forma de su integración en el poder judicial, el CEDS consideró que las personas que desempeñan las funciones de justicia de paz, no constituyen una categoría homogénea en materia de seguridad social, sino de manera funcional son equivalentes a los magistrados titulares conforme al artículo $12 \S 1$ de la Carta originaria, por lo tanto, en la práctica, pueden disfrutar de la seguridad social en virtud de un régimen de pensiones, un contrato de trabajo o una actividad profesional autónoma ${ }^{66}$.

Los argumentos que presentó el Estado italiano para justificar el trato diferenciado fueron: el procedimiento de selección, el mandato fijo, el trabajo a tiempo parcial, el servicio honorario, la remuneración mediante indemnización y el hecho de que las personas que desempeñan las funciones de justicia de la paz son designados como proveedores de servicios; mientras que los jueces titulares y las otras categorías de jueces legos, como los giudici onorari aggregati, desempeñan sus funciones de manera estable, continua y exclusiva.

El CEDS consideró que los argumentos vertidos por la parte demandada se refieren a meras modalidades de organización del trabajo y que, por lo tanto, no constituyen una justificación objetiva y razonable del trato diferenciado de las personas cuya equivalencia funcional ha sido reconocida ${ }^{67}$, lo que provoca un trato diferenciado en materia de seguridad social que contraviene el artículo E en relación con el artículo $12 \S 1$ de la $\mathrm{CSE}^{68}$.

${ }^{65}$ Reclamación 102/2013, Asociación Nacional de Magistrados de Paz vs Italia [Consulta: 6 de octubre de 2018], <http://hudoc.esc.coe.int/eng/\# ‘ "fulltext":["SOCIALSECU RITY"],"ESCDcType":[“FOND”,"Conclusion","Ob”],"ESCDcIdentifier":[“cc102-2013-dmerits-en"] $\}>$. La queja fue registrada el 2 de agosto de 2013.

${ }^{66}$ Idem. Reclamación 102/2013, párrafo 77.

${ }^{67}$ Idem. Reclamación 102/2013, párrafo 82.

${ }^{68}$ Idem. Reclamación 102/2013, párrafo 83. 
De igual manera relacionada con el principio de igualdad y la prohibición de discriminación se encuentra la queja colectiva 121/2016. En esta queja que se encuentra pendiente de resolución, la organización querellante, Equal Rights Trust (ERT) refiere que al modificarse en Bulgaria el 28 de julio de 2015 la Ley de Subsidios Familiares para Menores (FACA) viola la CSER en sus artículos 12 (derecho a la seguridad social), 16 (derecho a una protección social, jurídica y económica apropiada de la familia), 17 (derecho de los niños y jóvenes a una situación social, jurídica y económica adecuada; protección) en correlación con la cláusula de no discriminación establecida en el artículo E del mismo instrumento normativo.

Otras quejas colectivas que se encuentran pendientes de resolverse por el CEDS en los que se reclama la violación al derecho de la seguridad social son las siguientes ${ }^{69}$ :

\section{Cuadro 1. Quejas colectivas pendientes de resolverse por el CEDS}

\begin{tabular}{|c|c|}
\hline Queja colectiva & Resumen \\
\hline $\begin{array}{c}\text { Asociación Panhelénica de } \\
\text { Pensionistas del Grupo OTE } \\
\text { de Telecomunicaciones } \\
\text { (PAP-OTE) } \\
\text { vs. } \\
\text { Grecia } \\
\text { Queja n. }{ }^{\circ} 165 / 2018\end{array}$ & $\begin{array}{l}\text { La denuncia se registró el } 30 \text { de abril de } 2018 \text {. Se } \\
\text { refiere a los artículos } 12 \S 2,12 \S 3 \text { (derecho a la } \\
\text { seguridad social) y } 23 \text { (derecho de las personas de } \\
\text { edad a la protección social) de la CSER. } \\
\text { PAP-OTE sostiene que a pesar de que la juris- } \\
\text { prudencia del CEDS y de la jurisprudencia } \\
\text { nacional ha declarado la legislación destinada a } \\
\text { reducir las pensiones contraria a la Constitución } \\
\text { helénica y a la CSER, Grecia no se ha ocupado } \\
\text { del problema. }\end{array}$ \\
\hline $\begin{array}{c}\text { Sindacato autonomo } \\
\text { Pensionati Or.SA } \\
\text { vs. } \\
\text { Italy } \\
\text { Queja n. } .^{\circ} 167 / 2018\end{array}$ & $\begin{array}{l}\text { La queja se registró el } 11 \text { de mayo de } 2018 \text {. Se } \\
\text { refiere a los artículos } 12 \S 3 \text { (derecho a la segu- } \\
\text { ridad social) de la Carta de } 1961 \text { y al artículo } \\
4 \S 1 \text { (derecho de las personas de edad a la pro- } \\
\text { tección social) del Protocolo Adicional de } 1988 \\
\text { a la Carta de } 1961 \text {. El sindicato querellante } \\
\text { alega que las disposiciones del artículo } 1 \text { del } \\
\text { Decreto Legislativo } .^{\circ} 65 / 2015 \text { y del artículo } 1 \\
\text { (483) (e), de la Ley } 147 / 2013 \text { introducen medi- } \\
\text { das de regresión social injustificadas en mate- } \\
\text { ria de seguridad social. }\end{array}$ \\
\hline
\end{tabular}

${ }^{69}$ Quejas pendientes del CEDS, [Consulta: 6 de octubre de 2018], <https://www.coe. int/en/web/turin-european-social-charter/pending-complaints $>$ 


\begin{tabular}{|c|c|}
\hline Queja colectiva & Resumen \\
\hline $\begin{array}{c}\text { Unione sindacale di base } \\
\text { (USB) } \\
\text { vs. } \\
\text { Italia } \\
\text { Queja n. }{ }^{\circ} \text { 170/2018 }\end{array}$ & $\begin{array}{l}\text { La queja se registró el } 9 \text { de agosto de } 2018 \text {. Se } \\
\text { relaciona con los artículos } 1 \text { (el derecho a traba- } \\
\text { jar), } 4 \text { (el derecho a una remuneración justa), } 5 \text { (el } \\
\text { derecho de sindicación), } 6 \$ 4 \text { (el derecho de nego- } \\
\text { ciación colectiva - colectiva acción), } 12 \text { (el dere- } \\
\text { cho a la seguridad social), } 24 \text { (el derecho a la } \\
\text { protección en caso de despido) y E (no discrimi- } \\
\text { nación) de la CSER. } \\
\text { En este caso, USB se queja del abuso de los con- } \\
\text { tratos de trabajadores «socialmente útiles» por } \\
\text { parte de los municipios y organismos públicos } \\
\text { de Sicilia y Campania que contribuyen a hacer } \\
\text { que la situación de estos empleados del sector } \\
\text { público sea más precaria, lo que se traduce en la } \\
\text { inobservancia de las referidas disposiciones de } \\
\text { la CSER. }\end{array}$ \\
\hline
\end{tabular}

En contraposición a lo expuesto, existen casos en los que el CEDS no ha declarado la transgresión del derecho a la seguridad social, dentro de éstos, se encuentra la queja 42/2007 interpuesta por la Federación Internacional de los Derechos Humanos (FIDH) en contra de Irlanda ${ }^{70}$. En esta reclamación registrada el 26 de febrero de 2007, la FIDH sostuvo que la negativa de las autoridades irlandesas a permitir el acceso de pensionistas no residentes, beneficiarios de la pensión irlandesa contributiva de vejez al Free Travel Scheme infringe las obligaciones de Irlanda contenidas en los artículos $12 \S 4$ y 23 de la CSER en combinación con el artículo E del mismo ordenamiento.

En la queja interpuesta, el CEDS observó que la prestación en cuestión no constituye un derecho legal que pueda asimilarse a los beneficios derivados de la legislación de seguridad social, por lo tanto, no existe violación al artículo $12 \S 4$ de la CSER.

Por su parte, en la queja 43/2007 presentada por el Sindicato dos Magistrados do Ministério Público (SMMP) en contra de Portugal ${ }^{71}$, la denuncia tenía por objeto determinar si la exclusión de los miembros de la Fiscalía de

${ }^{70}$ Reclamación 42/2007 Federación Internacional de los Derechos Humanos (FIDH) vs. Irlanda, [Consulta: 4 de octubre de 2018], <http://hudoc.esc.coe.int/eng/\#\{“ESCD cIdentifier":[“cc-42-2007-dmerits-en"] \}>

${ }^{71}$ Reclamación 43/2007 Sindicato dos Magistrados do Ministério Público (SMMP) vs. Portugal, [Consulta: 5 de octubre de 2018], <http://hudoc.esc.coe.int/eng/\#\{“ESCD cIdentifier":[“cc-43-2007-dmerits-en"] \}>.La queja fue registrada el 17 de abril de 2007 
los beneficios del Servicio de Bienestar Social del Ministerio de Justicia (SSMJ) por disposición del Decreto Legislativo n. ${ }^{\circ}$ 212/2005, de 9 de diciembre de 2005 es coherente con la CSER. La SMMP afirmó que la situación en juego se trataba de una violación a los artículos $12 \S 1,12 \S 2$ y $12 \S 3$ de la CSER.

El CEDS al observar que parte de la queja se refería a los servicios de bienestar social, consideró que estaba fuera del alcance del artículo 12 de la CSER, y al no tener relación con los artículos $12 \S 1$ y $12 \S 2$ de la Carta revisada, pues la SMMP no reclamó que los cambios en el régimen de la seguridad social implementados por el Decreto Legislativo n. ${ }^{\circ}$ 212/2005 coloquen al sistema de seguridad social portugués en un nivel insuficiente para ratificar el Código Europeo de Seguridad Social o que éstos constituirían un obstáculo para mantener dicho sistema, por consecuencia, la queja se refiere al artículo $12 \S 3$ de la CSER.

Si bien el Decreto Legislativo transfirió a los miembros del Ministerio Público del SSMJ al régimen general de salud aplicable a todos los funcionarios del Estado (ADSE), para el CEDS no hay una diferencia en el alcance material y las modalidades prácticas de los dos esquemas, y mientras ambos sistemas brinden un nivel de seguridad social lo suficientemente amplio, por consecuencia no existe contravención al artículo $12 \S 3$ de la CSER.

En el caso de la queja 50/2008 interpuesta por la Confédération française démocratique du travail (CFDT) en contra de Francia ${ }^{72}$ se alegó que las normas que rigen la disolución de las fuerzas civiles francesas con base en Alemania no garantizan de forma adecuada los derechos establecidos en la CSER en sus artículos 4 (derecho a una remuneración justa), 12 (derecho a la seguridad social), 18 (derecho a ocupar una ocupación remunerada en el territorio de otras Partes) y 19 (derecho de los trabajadores migratorios y sus familias a la protección y asistencia) en correlación con el artículo E del mismo ordenamiento. En concreto la CFDT impugnó la negativa de las autoridades francesas a conceder a los funcionarios civiles de las fuerzas francesas en Alemania el beneficio del artículo 6 del Decreto 70-79, de 27 de enero de 1970.

En lo concerniente a este caso, el Comité consideró que no es necesario examinar si las quejas presentadas por la organización querellante se encontraban en el ámbito de las disposiciones sustanciales invocadas como transgredidas, debido a que los denunciantes se encontraban contratados bajo especiales condiciones de contratación que no pueden considerarse como discriminatorias.

72 Reclamación 50/2008 Confédération française démocratique du travail (CFDT) vs. Francia, en: [Consulta: 8 de octubre de 2018], <http://hudoc.esc.coe.int/eng/\# \{“ESCD cIdentifier":[“cc-50-2008-dmerits-en"] \}>. La queja fue registrada el 1 de abril de 2008. 
Respecto de la queja 73/2011 presentada por el Syndicat de Défense des Fonctionnaires (SDF) en contra de Francia ${ }^{73}$, la organización sindical alegó que las normas sobre accidentes de trabajo se aplicaron incorrectamente, especialmente en lo que respecta al derecho de reconocimiento de un accidente de trabajo en caso de depresión o ansiedad. El sindicato expuso diversos ejemplos para sustentar que la referida deficiencia tiene consecuencias adversas para todos los funcionarios públicos y para los empleados reasignados de France Télécom y La Poste en particular.

Después de analizar el asunto, el CEDS por unanimidad consideró que a los funcionarios públicos, en general, y a los funcionarios de France Télécom y La Poste, en particular, no se les impide disfrutar del derecho al reconocimiento de los accidentes laborales (incluidos los causados por la depresión). Además, de que valdría la pena estudiar la aplicación práctica de las normas jurídicas de Francia sobre los accidentes del trabajo caso por caso. Las posibles críticas a la duración de los procedimientos judiciales y a las formas de compensación proporcionadas por parte de la SDF en los casos particulares que expone, no pueden conducir a la conclusión de que la situación jurídica es contraria al artículo 12 de la CSE.

El mismo razonamiento fue aplicado por el CEDS respecto de las deficiencias atribuidas por la SDF a las medidas relativas al acoso psicológico y la inversión de la carga de la prueba debido a la no incorporación de la Directiva $2000 / 78 / \mathrm{CE}$ de 27 de noviembre de 2000 a la legislación francesa antes del 2 de diciembre de 2003.

Por su parte, en la reclamación colectiva 108/2014 presentada por la Sociedad finlandesa de derechos sociales en contra de Finlandia ${ }^{74}$, la organización sostuvo que el Estado finlandés infringe el artículo $12 \S 3$ de la CSER al no mantener un sistema de seguridad social en un nivel satisfactorio y elevarlo de forma progresiva al nivel más alto. En lo esencial, la querellante reclamó que las prestaciones de desempleo para las personas de edad se han reducido de manera gradual y el nivel de la asignación básica así como la subvención del mercado laboral se encontraban por debajo de los requerimientos que exige la CSER.

La organización afirmó que, anteriormente, las personas de edad que quedaban desempleadas tenían derecho a una prestación por desempleo

${ }^{73}$ Reclamación 73/2011, Syndicat de Défense des Fonctionnaires (SDF) vs. Francia, [Consulta: 8 de octubre de 2018], <http://hudoc.esc.coe.int/eng/\# \{ “ESCDcIdentifier":[“cc73-2011-dmerits-en"] $\}>$. La queja se registró el 19 de julio de 2011.

${ }^{74}$ Reclamación 108/2014, Sociedad finlandesa de derechos sociales en contra de Finlandia [Consulta: 3 de octubre de 2018], <http://hudoc.esc.coe.int/eng/\#\{“ESCD cIdentifier":[“cc-108-2014-dadmissandmerits-en”] $\}>$. La reclamación fue registrada el 29 de abril de 2014. 
prolongada relacionada con las ganancias, si habían agotado su derecho a quinientos días de beneficios cuando la persona cumpliera cincuenta y cinco años de edad. Asimismo, la prestación de desempleo prolongada relacionada con las ganancias se abonaba hasta que la persona alcanzaba la edad de sesenta años, si a partir de ese momento le correspondía el derecho a una pensión de desempleo. Empero, entre 2011 y 2014 al modificarse el sistema de beneficios de desempleo, la pensión de desempleo quedó abolida, por lo que una persona desempleada ahora debe esperar hasta la edad de sesenta y tres años para recibir una pensión de vejez.

En el contexto de la presente queja, el CEDS consideró que aumentar el límite de edad para recibir ciertos beneficios y eliminarlos de manera gradual para los trabajadores más jóvenes puede ser legítimo, de acuerdo con la situación del empleo en el país, además de que para Finlandia, la prolongación de las carreras profesionales ha sido una de las cuestiones prioritarias en los últimos años, lo que condujo, entre otras cosas, a la introducción de una reforma integral de las pensiones con un plan de jubilación flexible.

Asimismo, el Comité consideró que las medidas denunciadas se introdujeron con el objetivo de mantener a los trabajadores de mayor edad en la fuerza de trabajo durante más tiempo, y no impiden que los miembros de la sociedad continúen disfrutando de una protección efectiva contra los riesgos sociales y económicos. Incluso el CEDS determinó que las medidas adoptadas fueron proporcionales al objetivo, en particular porque el límite de edad para recibir las prestaciones de desempleo prolongadas relacionadas con las ganancias es menor para los desempleados de más edad y aumenta de forma gradual para las generaciones más jóvenes.

A su vez, al observar el CEDS que las personas en Finlandia pueden recibir una pensión de vejez temprana a la edad de sesenta y tres años y una pensión completa a los sesenta y cinco años, encontrándose la prestación por desempleo disponible para todos por una duración de quinientos días (que excede la requerida por el Código Europeo de Seguridad Social), y que un período prolongado de protección sigue estando disponible para las personas de edad desempleadas que han agotado su derecho al seguro de desempleo, por consecuencia provoca que no exista violación al artículo $12 \S 3$ de la CSER.

A lo anterior se adiciona que en sus Conclusiones de 2013 el Comité consideró que la situación en Finlandia era conforme con el artículo $12 \S 2$ al abarcar las nueve ramas con un alcance personal satisfactorio, y que las pensiones relacionadas con los ingresos se habían mantenido en un nivel estable en relación con los salarios (la tasa de compensación neta era de alrededor del $65 \%$ ), mientras que la tasa de compensación del seguro de desempleo era de alrededor del $60 \%$ de la retribución neta.

Otro ejemplo infructuoso lo constituye la reclamación colectiva n. ${ }^{\circ}$ 120/2016 presentada por Fellesforbundet para Sjøfolk (FFFS) en contra 
de Noruega ${ }^{75}$. En este asunto el sindicato querellante denunció la contravención a las disposiciones del artículo 12 (derecho a la seguridad social) en correlación con la cláusula de no discriminación de la CSER, con motivo de la exclusión de los marineros españoles que trabajaban en buques de pabellón noruego de los regímenes de seguridad social por razón de su nacionalidad.

El Comité consideró que la cuestión objeto de la queja al relacionarse con la coordinación de los regímenes de seguridad social se encontraba dentro del alcance del artículo $12 \S 4$ de la CSE y de la reserva realizada a este numeral por Noruega, pues la situación denunciada surgió cuando este país estaba obligado por la Carta de 1961 (ratificada el 26 de octubre de 1962) y no por la Carta revisada (ratificada el 7 de mayo de 1997).

A pesar de que la Carta originaria no prevé ninguna cláusula de reserva, el Comité aceptó que las reservas son procedentes, cuando se han aceptado el número mínimo de disposiciones previstas en el artículo 20 de la Carta de $1961^{76}$, siempre que no sean demasiado generales y no contravengan el objeto y propósito de la CSE, tal y como lo dispone el principio general de derecho internacional codificado en el artículo 19 c) del Convenio de Viena sobre el Derecho de los Tratados.

Para el CEDS al determinar que la aceptación de Noruega a las disposiciones de la CSE se mantuvo por encima del mínimo y la reserva cumplía con las condiciones del Convenio de Viena sobre el Derecho de los Tratados, por consecuencia determinó que el Estado noruego no estaba obligada a conceder, en virtud de la Carta de 1961, los derechos de seguridad social a los marineros extranjeros no domiciliados en Noruega.

Por último, cabe mencionar la queja colectiva 113/2014 presentada por la Unione Italiana del Lavoro UIL Scuola-Sicilia en contra de Italia. En este asunto registrado el 14 de noviembre de 2014, el sindicato querellante alegó que las normas italianas de protección social, y en particular el Decreto interministerial n. ${ }^{\circ} 83473$, de 1 de agosto de 2014, sólo otorgaba a las empresas el derecho a recibir asistencia de la Cassa integrazione guadagni (fondo de despido), y excluía a los organismos de formación establecidos en la forma de asociaciones sin fines de lucro, en contravención a la CSER en sus artículos

75 Reclamación 120/2016, Fellesforbundet para Sjøfolk (FFFS) vs Noruega, [Consulta: 3 de octubre de 2018], <http://hudoc.esc.coe.int/eng/\#\{“ESCDcIdentifier":["cc-1202016-dadmiss-en"] $\}>$

${ }^{76}$ Conclusiones XIV-1 (1998), Países Bajos, artículo 6\$4, [Consulta: 4 de octubre de 2018], <http://hudoc.esc.coe.int/eng/\# \{“ESCDcIdentifier”:["XIV-1/def/NLDANT/6/4/ EN"] $\}>$ y Conclusiones VII (1981), Alemania, artículo 6\$4, [Consulta: 1 de octubre de 2018], <http://hudoc.esc.coe.int/eng/\#\{“fulltext”:[“ConclusionVIIgermaby”],"ESCDcId entifier":[“VII/def/DEU/6/4/EN"],"ESCDcType":[“FOND”,,"Conclusion","Ob”]\}> 
12 (derecho a la seguridad social), 25 (derecho de los trabajadores a la protección de sus créditos en caso de insolvencia de su empleador) en combinación con la cláusula de no discriminación contenida en el artículo E del mismo ordenamiento.

Después de advertir que el sistema de prestaciones por desempleo en Italia establece varias categorías de prestaciones y cubre a todos los trabajadores del sector privado, mientras que los amortiguadores sociales sólo resultan aplicables a situaciones muy específicas e incluso, de acuerdo con las distintas reformas, se han introducido criterios más restrictivos para acceder a los mismos, con el objetivo final de reemplazar este régimen por un nuevo sistema de desempleo, el CEDS determinó que no se transgrede el artículo $12 \S 1$ de la $\mathrm{CSE}^{77}$.

En lo concerniente al artículo $12 \S 3$ de la CSE, si bien la U.I.L. ScuolaSicilia refirió que a 2650 personas del sector de capacitación siciliano se les negó el acceso a los beneficios de los amortiguadores sociales después de la adopción del Decreto Interministerial n. ${ }^{\circ} 83473 / 2014$, el CEDS decretó su imposibilidad para pronunciarse sobre la desproporción o exceso en el tratamiento de los amortiguadores sociales por excepción, toda vez que la parte reclamante no proporcionó información sobre el número total de operarios que tuvieron acceso a las medidas impuestas, tampoco detalló el porcentaje de esos 2650 trabajadores en comparación con todos los trabajadores en la región de Sicilia, ni la información sobre el contexto económico de los centros de capacitación, sus posibles dificultades económicas o el posible impacto de estas restricciones en los trabajadores de estos centros ${ }^{78}$.

Además, en busca de una solución temporal, el Comité consideró que al haberse adoptado el Decreto interministerial n. ${ }^{\circ}$ 90973/2015 en la región siciliana, se introdujo un aumento en los recursos asignados por excepción, lo que al permitir a las regiones extender la protección en el contexto de los amortiguadores sociales a una parte de los centros de capacitación ${ }^{79}$, hace improcedente la violación del artículo $12 \S 3$ de la CSE.

\section{PROBLEMÁTICA DE LOS MECANISMOS DEL COMITÉ EUROPEO DE DERECHOS SOCIALES}

Los sistemas de informes y de reclamaciones se complementan para lograr la justiciabilidad directa del derecho a la seguridad social. Empero al depender de la información que proporcionen las partes contratantes y ante la

${ }^{77}$ Reclamación 113/2014, Unione Italiana del Lavoro UIL Scuola-Sicilia vs Italia, [Consulta: 5 de octubre de 2018], <http://hudoc.esc.coe.int/eng/?i=cc-113-2014-dmerits-en>

${ }^{78}$ Idem.

${ }^{79}$ Idem. 
falta de ejecutabilidad directa de las conclusiones y decisiones que emite el CEDS, ambos mecanismos de control dependen en gran medida de la voluntad política de los Estados, lo cual debilita la efectividad de los mismos.

A la fecha la CSE en su versión originaria y revisada no forman parte del derecho de la Unión Europea y ambos instrumentos internacionales son escasamente utilizados por el Tribunal de Luxemburgo al emitir sus fallos, a pesar de que ambos contienen el más completo catálogo de derechos sociales. Esto por supuesto ha contribuido al escaso diálogo que existe entre el CEDS y el Tribunal de Justicia de la UE como partes integrantes de los dos sistemas representativos de derechos humanos que coexisten en Europa.

A lo anterior se adiciona que en las reclamaciones colectivas, con excepción de Finlandia, los entes legitimados son las organizaciones sindicales gubernamentales, que en su mayoría, se especializan e interesan en los conflictos de índole laboral, por lo que se estima necesaria el conocimiento y resolución de peticiones individuales por parte del CEDS en los que exista una vulneración de todos los derechos sociales reconocidos en la CSE y en la CSER, lo cual fortalecería la justiciabilidad directa de este tipo de derechos y se evitaría el recurrir al complejo y prolongado sistema de denuncias individuales seguido ante el Tribunal Europeo de Derechos Humanos que sólo permite reclamar las violaciones de derechos sociales en conexión con derechos sustantivos de corte individual y procedimental.

Es preciso que los derechos sociales cuenten con garantías adecuadas y efectivas que posibiliten su accionabilidad con la mayor prontitud posible, pues la mayoría de ellos son paliativos en casos de necesidad y para la realización del ser humano en su entorno individual y colectivo.

\section{FUENTES DE INFORMACIÓN}

Guiglia, G. «El derecho a la vivienda en la Carta Social Europea: A propósito de una reciente condena a Italia del Comité Europeo de Derechos Sociales», UNED, Revista de Derecho Público, n. ${ }^{\circ}$ 82, septiembre-diciembre 2011.

JiMENA QuesADA, L. «Defensa y garantía de los derechos sociales por el Consejo de Europa: Atención Especial al Comité Europeo de Derechos Sociales», en ALFONso Mellado, C. L. et al., La jurisprudencia del Comité Europeo de Derechos Sociales frente a la crisis económica, Bomarzo, España, 2014.

— «Crónica de la Jurisprudencia del Comité Europeo de Derechos Sociales-2012», Revista Europea de Derechos Fundamentales, n. ${ }^{\circ}$ 20/2 ${ }^{\circ}$, Semestre 2012.

SAlCEdo Beltrán, M. ${ }^{a}$ C. «Crisis económica, medidas laborales y vulneración de la Carta Social Europea», Revista Europea de Derechos Fundamentales, n. ${ }^{\circ} 22 / 2^{\circ}$, Semestre 2013. 
Tratado de LA Unión Europea (versión consolidada), [Consulta: 22 de septiembre de 2018], disponible en $<$ http://eur.lex.europa.eu/resource.htm?uri=cellar:2bf140bfa3f8-4ab2-b506fd71826e6da6.0005.02/DOC_1\&format=PDF>

Carta Social Europea, [Consulta: 30 de septiembre de 2018], disponible en $<$ http:// www.acnur.org/t3/fileadmin/scripts/doc.php?file=t3/fileadmin/Documentos/ BDL/2002/1934>

Protocolo de Enmienda a la CARTa social Europea, de 21 de octubre de 1991 [consulta: 29 de septiembre de 2018], disponible en $<$ http://www.acnur.org/t3/ fileadmin/Documentos/BDL/2003/1899.pdf?view=>

Protocolo Adicional a la CARTA Social Europea de 1995 [consulta: 9 de octubre de 2018], <http://www.juntadeandalucia.es/empleo/anexos/ccarl/2_267_1.pdf>

Carta Social Europea Revisada, [Consulta: 11 de agosto de 2018], disponible en $<$ http://rm.coe.int/168047e013>

RECOMENDACIÓN 839 DE 28 DE SEPTIEMBRE DE 1978 [consulta: 1 de octubre de 2018], disponible en <https://digitallibrary.un.org/record/6650/files/E_CN.4_1333-ES. pdf $>$

RESOLUCión 2180 (2017). «El "proceso de Turín”: refuerzo de los derechos sociales en Europa», Asamblea Parlamentaria [Consulta: 24 de agosto de 2018], disponible en <http://assembly.coe.int/nw/xml/XRef/Xref-XML2HTML-en.asp?fileid $=23993$ \&lang $=$ en $>$

Conclusiones y Quejas Colectivas del Comité Europeo de Derechos Sociales, en: http://hudoc.esc.coe.int/eng/\#\{“ESCDcType”.

QUEJAS PENDIENTES DEL CEDS, en: https://www.coe.int/en/web/turin-european-social-charter/pending-complaints. 


\title{
EL DERECHO A LA SEGURIDAD SOCIAL ANTE EL COMITÉ EUROPEO DE DERECHOS SOCIALES
}

\author{
The right to Social Security before \\ the European Committee of Social Rights
}

\author{
Verónica Lidia Martínez Martínez \\ Profesora-Investigadora doctora de la Universidad Anáhuac \\ Investigadora Nacional del Sistema Nacional de Investigadores \\ del Consejo Nacional de Ciencia y Tecnología (México) \\ marb_cap@hotmail.com
}

http://dx.doi.org/10.18543/ed-67(1)-2019pp259-291

\section{Copyright}

Estudios de Deusto es una revista de acceso abierto, lo que significa que es de libre acceso en su in tegridad. Se permite su lectura, la búsqueda, descarga, distribución y reutilización legal en cualquier tipo de soporte sólo para fines no comerciales, sin la previa autorización del editor o el autor, siempre que la obra original sea debidamente citada y cualquier cambio en el original esté claramente indicado

Estudios de Deusto is an Open Access journal which means that it is free for full access, reading, search, download, distribution, and lawful reuse in any medium only for non-commercial purposes, without prior permission from the Publisher or the author; provided the original work is properly cited and any changes to the original are clearly indicated. 